\title{
SCADA and Distributed Control System of a Chemical Products Dispatch Process
}

\author{
Omar Chamorro-Atalaya ${ }^{1}$, Dora \\ Arce-Santillan $^{2}$ \\ Facultad de Ingeniería y Gestión \\ Universidad Nacional Tecnológica \\ de Lima Sur (UNTELS) \\ Lima- Perú
}

\author{
Guillermo Morales-Romero ${ }^{3}$, \\ Nicéforo Trinidad-Loli ${ }^{4}$, Adrián \\ Quispe-Andía ${ }^{5}$ \\ Universidad Nacional de Educación \\ Enrique Guzmán y Valle \\ Lima-Perú
}

\author{
César León-Velarde ${ }^{6}$ \\ Universidad Tecnológica del Perú \\ (UTP) \\ Lima-Perú
}

\begin{abstract}
The objective of this article is to show the application of a supervision, control and acquisition system of an industrial network of chemical products, for which the design of the control logic and the architecture of the industrial network on Profibus-DP protocols is described and Ethernet, with a peripheral terminal station ET-200, through the Siemens CP433 programmable logic controller and level sensor sensors, coupled to radar-type transmitters with an accuracy of $\pm 0.5 \mathrm{~mm}$. As findings of the implementation of the control system, it was possible to demonstrate the optimal regulation of the filling system of the 3-compartment trucks with a capacity of 300 Kilos each, generating the elimination of spills of the chemical product, as well as the reduction of polluting particles in the work environment. Finally, as a direct consequence, the productivity of the company was improved, which is a relevant aspect at the level of planning, management and direction.
\end{abstract}

Keywords-Distributed control; supervision; acquisition; chemical products; dispatch of chemical supplies

\section{INTRODUCTION}

Organizations dedicated to the distribution and dispatch of chemical products are susceptible to generating negative environmental impacts due to the lack of technological strategies that minimize risks of spillage [1], [2]. And it is necessary to be aware of and highlight the risks and consequences of not supervising or monitoring the correct process of transporting or transferring the chemical input for its storage and dispatch [3]. When these processes lack or are not linked to technological tools, but on the contrary respond to strictly manual processes, in which the personnel or operator is exposed to these chemical inputs, effects are totally adverse to health, since they are less likely intrinsic generates toxicity and pollutes the environment [4]. The maneuvers in the dispatch processes of chemical inputs when they are manual or executed by some personnel, increase the risk of spills, which, as already stated, affects the human being and the environment, but also affects production, due to actions corrective measures that must be generated at that moment [5]. It is clear that these organizations must get involved with technologies that reduce all types of spill risk, since the negative consequences are derived from there [6].

Industrial automation is currently used as a tool that contributes to improving various stages immersed in production processes, thus improving aspects related to precision in component dosing, accuracy in the sequencing of events, self-regulation and improvement of the location of the final product [7]. Automating a process guarantees the logical control relationship between sensors and actuators of a process, however through communication protocols it is necessary to seek to implement supervision, control and data acquisition systems [8]. These communications protocols guarantee the adequate interface in the sensors and actuators of a process, interrelating it through an industrial network, which allows the supervision and monitoring in real time of the variability of the indicators during the execution of the production process $[9$, 10].

Distributed control systems (DCS) allow an industrial plant to integrate its different production processes, linking the various programmable logic controllers (PLC), which are associated from a logical point of view to sensors and actuators, thus guaranteeing a fluid communication of data, which allows making decisions from the generation and processing of information [11, 12]. Referring to a distributed control system implies the generation of relevant data, which goes beyond operational aspects, becoming linked to very useful and important information systems at a strategic level in an organization [13]. With the purpose of supervising, monitoring and acquiring data for decision-making on aspects related to the operation or operation of an industrial process, SCADA systems (Supervisory Control and Data Acquisition) are used [14-17]. The application of SCADA systems is diverse, however among the processes that use it the most are electricity generation, natural gas, mining deposits, thermal systems, oil pipelines and chemical products dispatch [18-20]. One aspect to highlight in SCADA systems is that they allow in a friendly way to show the behavior of the critical variables in a process, becoming a strategic element at the industrial level, integrally linking geographically dispersed subsystems arranged in a plant [21-23].

It is then justifiable from the point of view of the monitoring, supervision and control capacity, the integration of DCS systems and SCADA systems [24-26]. As its application is diverse and by using different communication protocols as interface elements, its contribution is relevant, even more it is linked to the improvement of the operating and working conditions of the operators and their environment with the environment [27-29]. 
Under the above, the purpose of this article is to contribute through the description of the application of distributed control systems (DCS) under their integration to the SCADA system in a chemical products distribution company; seeking to reduce the remnants or spills of these inputs during their dispatch or filling in distribution trucks; guaranteeing the reduction of pollutants in the work environment and consequently eliminating any adverse effect on the personnel working in the plant.

\section{LITERATURE REVIEW}

In relation to relevant studies on this topic, we have in [30], which highlights the importance of the use of the SCADA system and its integration in the architecture of industrial processes, in which the performance and safety of processes related to oil industry or chemical inputs. In the same line of research in [31], a proposed solution is described for a process related to oil as a chemical input in which the SCADA system guarantees safety from the detection of abnormal events or events, thus avoiding any effect adverse on staff and work environment.

It should also be noted that this scientific article is supported by two studies already published in [32-34] which detail the composition of the industrial network that allows automating the chemical products dispatch process, as a solution to the reduction of pollutants due to spillage of the input due to a bad maneuver by the operators; These studies also highlight that as an effect of supervising, controlling and monitoring the dispatch system, from the perspective of improving the filling precision of the transport truck tanks, another positive effect, quite apart from the reduction of pollutants, is productivity improvement, a very relevant contribution to the organization, and which gives sustainability to a large-scale solution proposal such as the implementation of a distributed control system integrated into a SCADA system.

The implementation of intelligent systems through hardware and software, allow to guarantee the control of the operating parameters and variables of the industrial processes $[35,36]$.

\section{Control Philosophy AND ARChitecture OF THE DISTRIBUTED CONTROL NETWORK}

In order to understand the control logic that allows automating the chemical products dispatch process, in a simplified way the control philosophy represented in the flow diagram is shown in Fig. 1.

In the flow chart, two sensors are established that will determine the correct location of the containers for the filling process; if his position is not adequate, he will not proceed to execution; furthermore, only if the filling level of the container is adequate, a sensor will establish that the valves should be closed and proceed to fill the next container; It is necessary to indicate that the number of compartments to fill in a truck storing the chemical product is three.

In Fig. 2, the location and disposition of the three sources that contain the chemical product (Acetic acid) are schematized, and that from displacement pumps, valves controlled by electric actuator, overfill sensors, the same ones that were mentioned in the flow chart above; and making use of Siemens CP443 programmable logic controllers, I will proceed with the programming logic that establishes the link between the input and output elements of the process.

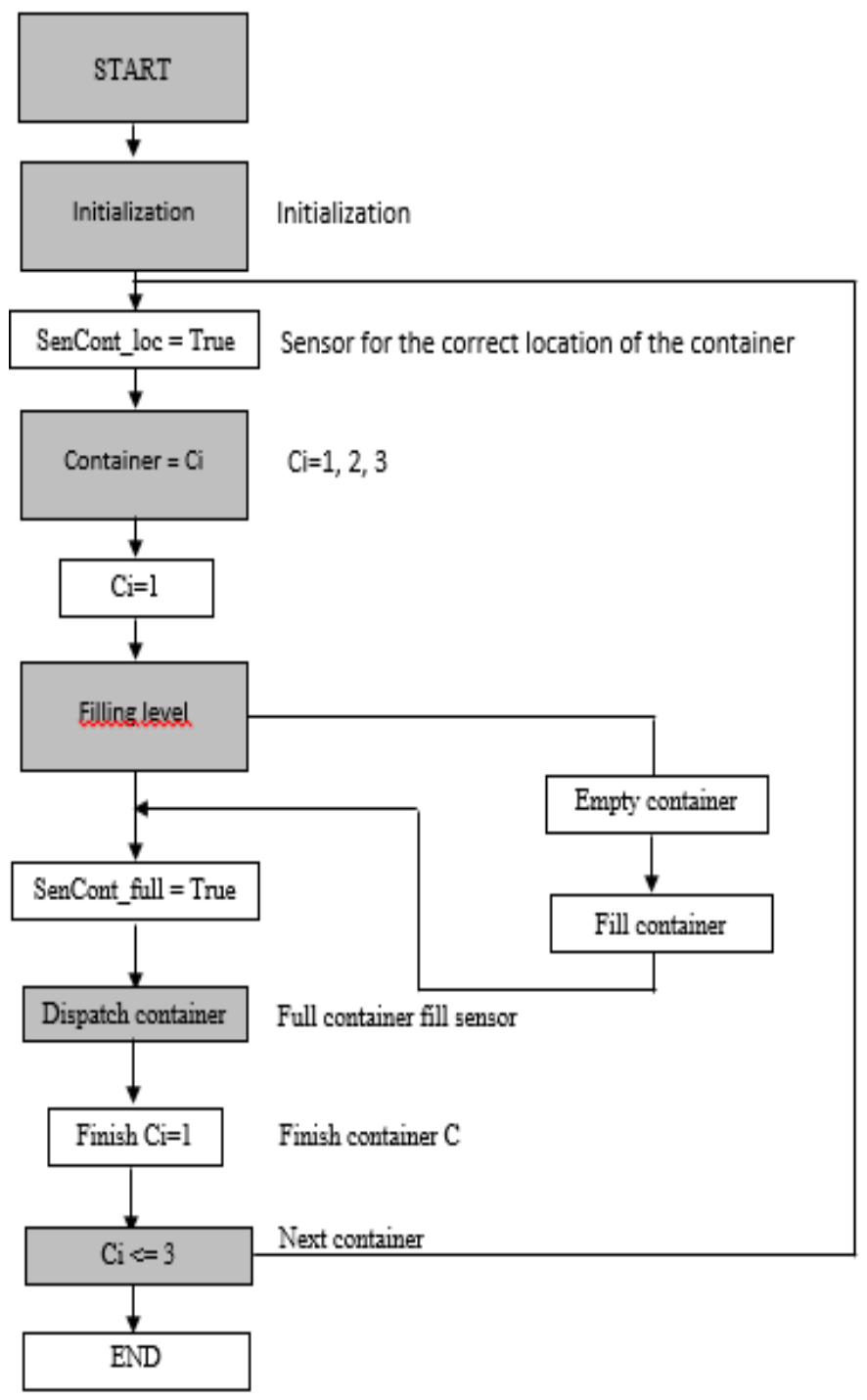

Fig. 1. Control Philosophy of the Chemical Product Dispatch Process. 


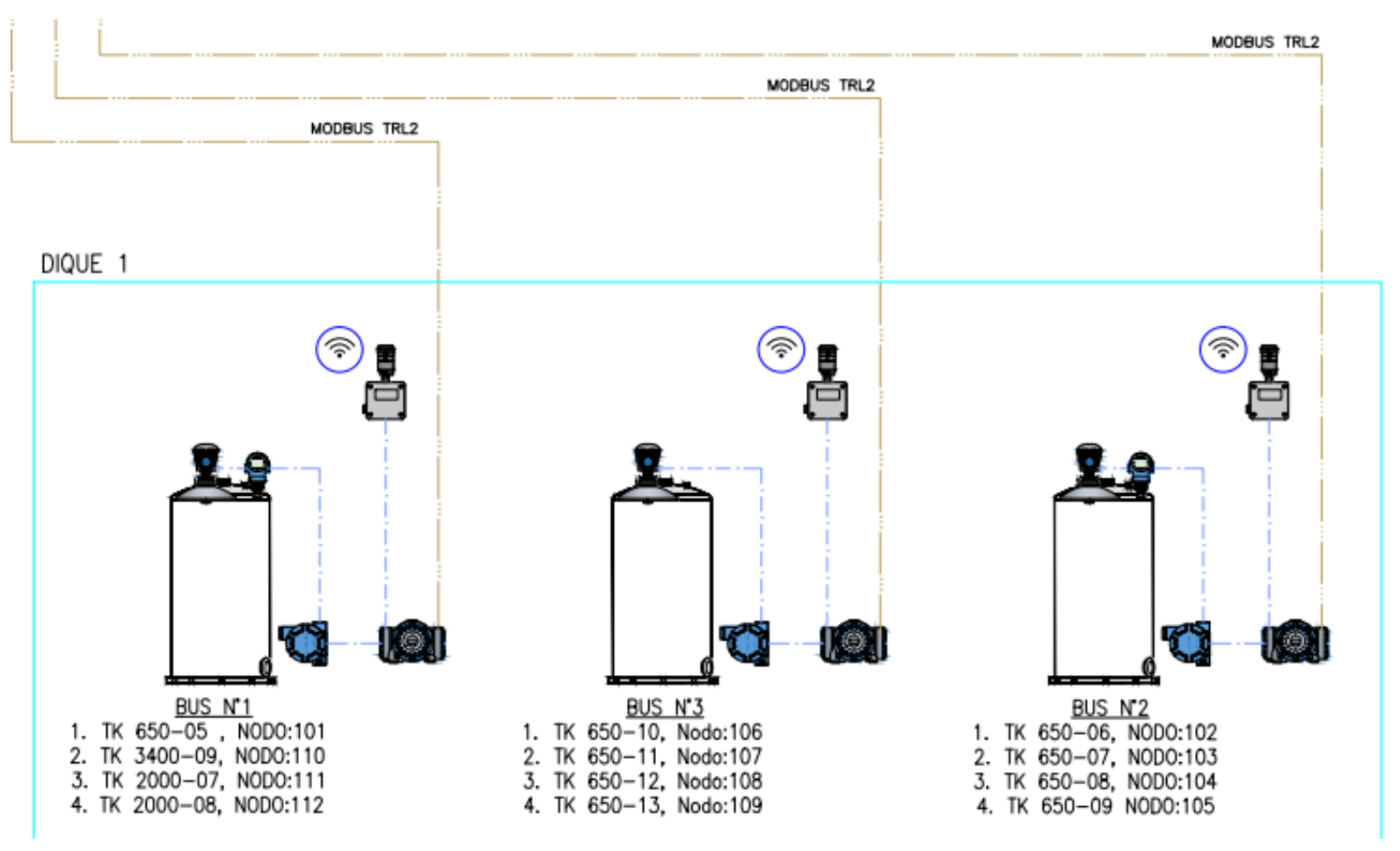

Fig. 2. Layout of Chemical Storage Tanks.

In Fig. 3, the connection between the sensors, actuators, scale zone and displacement pumps for filling with respect to the chemical product packaging trucks is shown; It should be noted that the pumps in operation operate in remote mode and in automatic sequence; in such a way that the valves also respond to a similar operating logic, that is, in remote mode and automatic sequence, which indicates that it is open; The displacement pump as well as the valves will always be monitored through the supervision and data acquisition system, the same as from the WinCC runtime Project system will allow the activation and shutdown of the mentioned elements and start the dispatch process. It should be noted that the valve is a 3 " butterfly type that is located on the second level of the truck station between the $45^{\circ}$ elbow and the start of the stainless steel hose. This system developed through the WinCC Runtime Project system will trigger an alarm 300 kilos before reaching the indicated weight for that compartment.

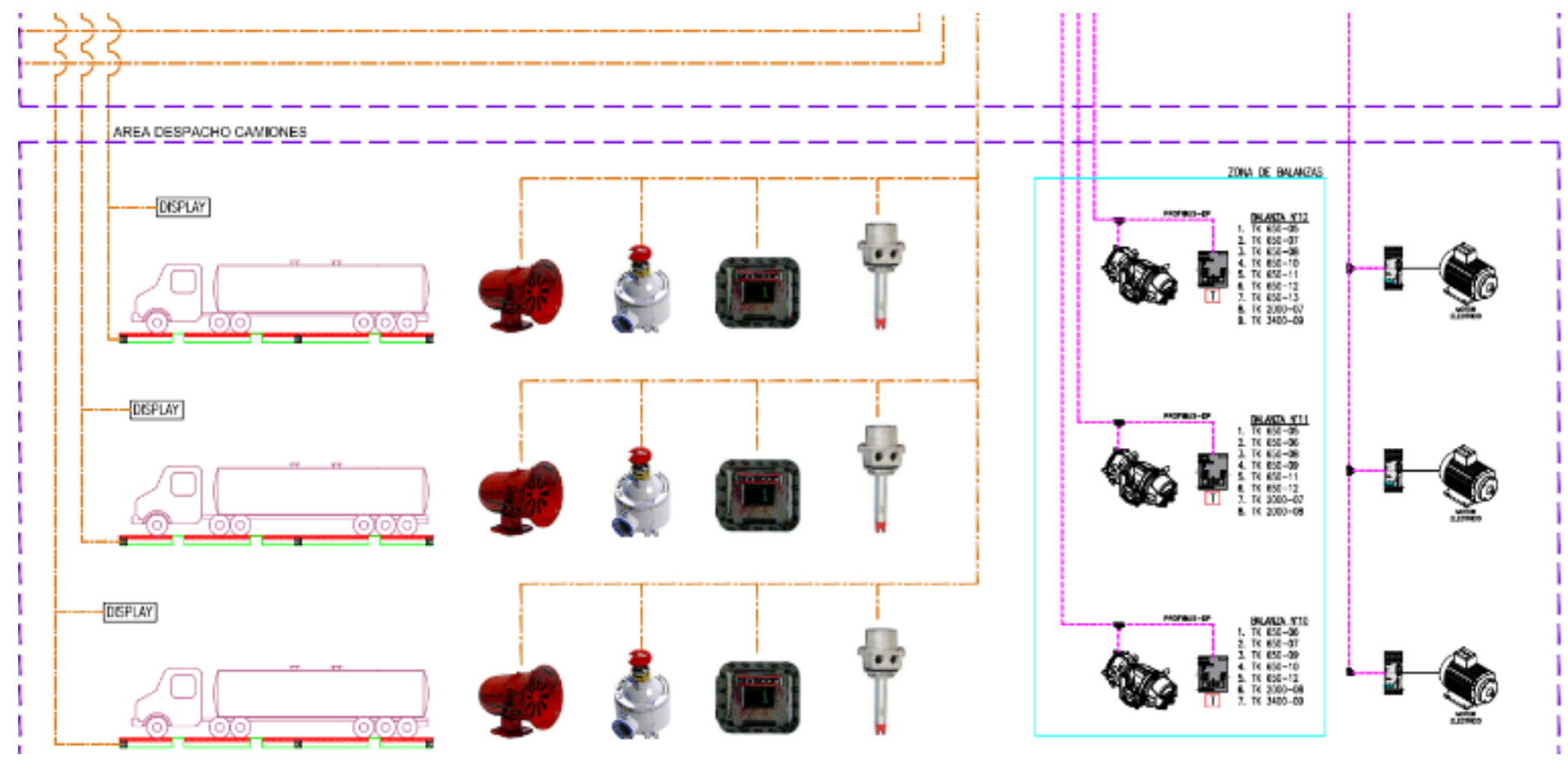

Fig. 3. Connection between Sensors, Actuators, Scale Zone and Displacement Pumps with respect to Packaging Trucks. 


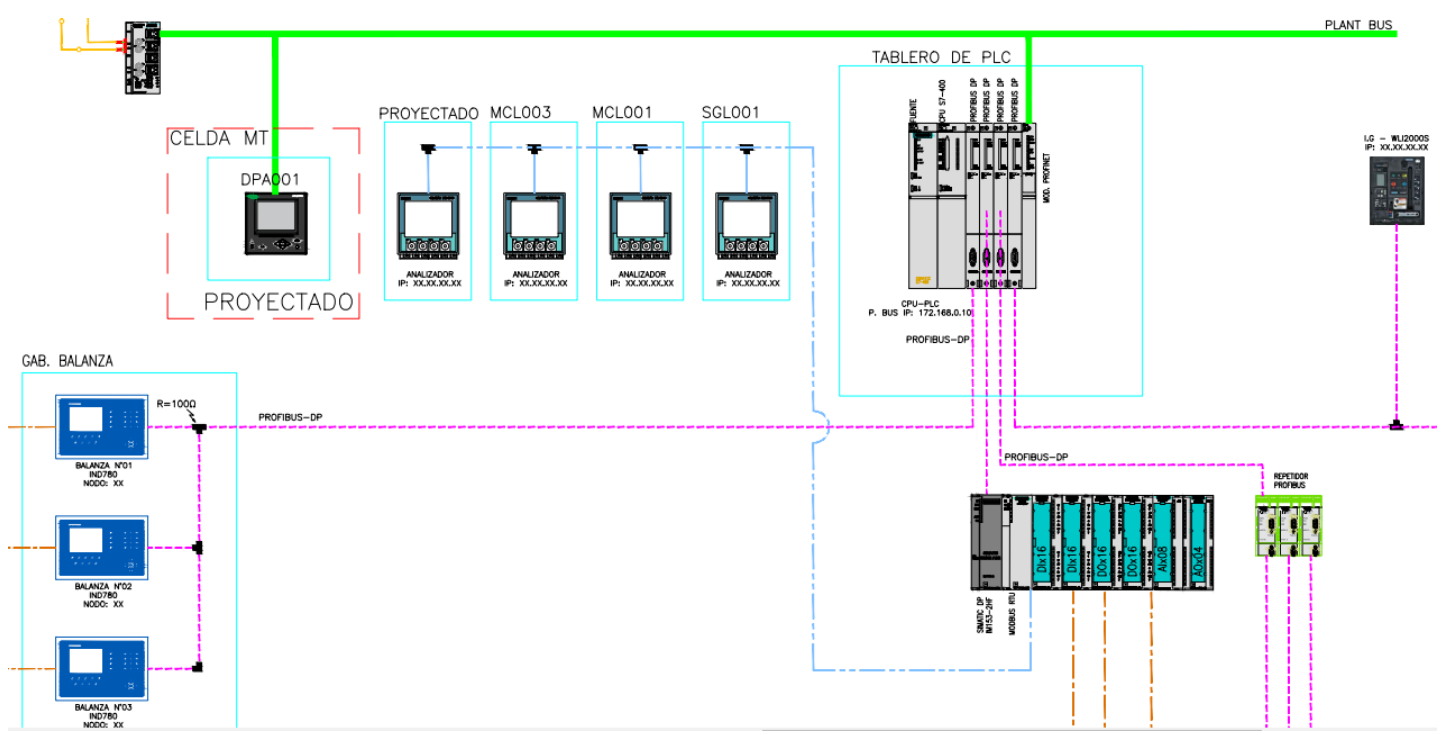

Fig. 4. Connection of Automated Industrial Network System Components.

The data server of the industrial network will be located in the server room and will be interconnected through a fiber optic network with the instrumentation equipment and located in the industrial instrumentation cabinets. The communication switch of the control system will allow the interconnection and exchange of information between the programmable logic controller and the data server, for this reason they must be installed in the same cabinet mentioned above, in accordance with the Control architecture, shown in the Fig. 4. For the monitoring of electrical variables, it is considered that all the data received from the multifunction meters will be sent to the data server for its proper use; in such a way that the displacement pumps must be composed of local control pushbuttons (located in the field, for starting and stopping the engine), selectors and status indicators. All remote start and stop signals coming from each programmable logic controller will be using the control logic and sent to the control center through Profibus DP communication.

\section{Control Board And Development of THe ScadA SYSTEM CONFIGURATION}

\section{A. Control Panel}

In Fig. 5, the electrical control cubicle is shown in which the main switch that energizes the entire control system of the previously selected transfer pump is enabled.

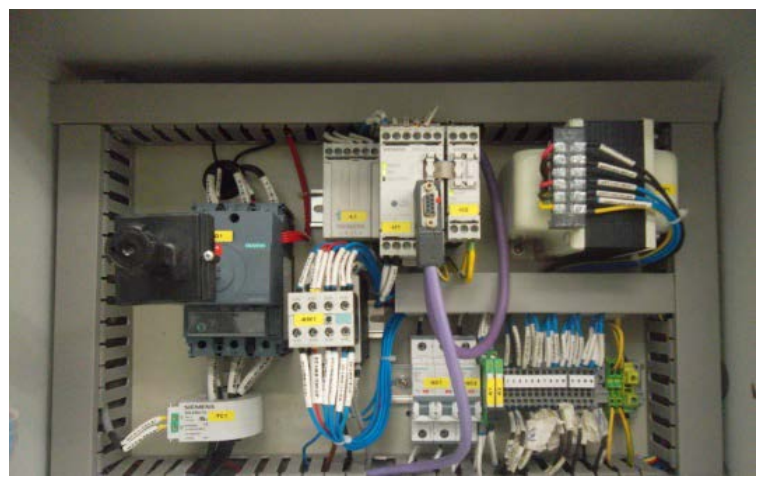

Fig. 5. Control Cube where the Central Switch is Located.
In Fig. 6, it is shown that to confirm that there is no blockage enabled in the field, this due to the incorrect location of the chemical product packaging trucks, it is necessary that the state of the switches that do not have the insurance be verified in the field placed. When the safety lock is in stop mode, it will prevent the transfer pump from being controlled from the control room in automatic mode.

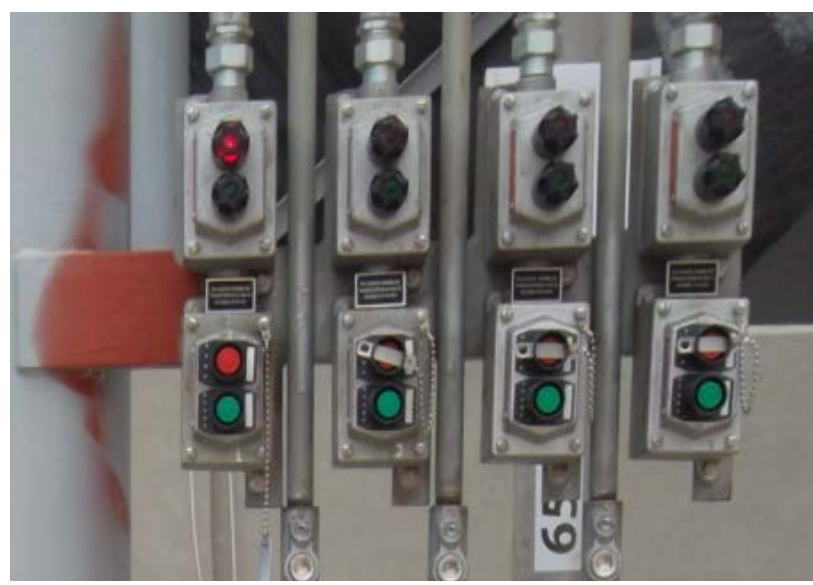

Fig. 6. Safety Switch Status.

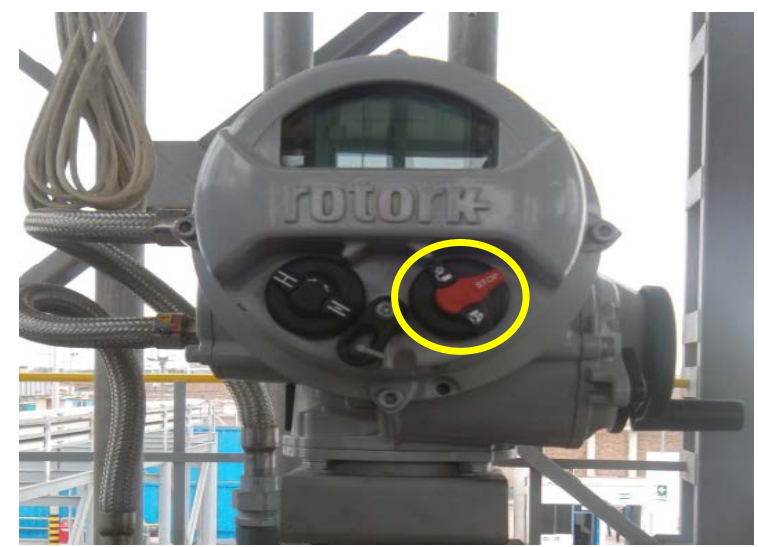

Fig. 7. Automatic Remote Actuation Switch and Scale Platform. 
In Fig. 7, the scale platform is shown, in which it will be verified that the selector is in the remote mode position, as shown in the figure. It should be noted that remote and automatic operation is achieved in the control mode shown.

\section{B. SCADA System Configuration}

A first relevant aspect for the configuration of the SCADA system is related to access security, the criteria of which has been considered at the time of making the configuration, for which the operation of the equipment has been restricted only to authorized users; in such a way as to avoid that personnel outside the operation of the plant can mainly start up equipment without prior permission; that is, only by entering the username and password can they be enabled. Fig. 8 shows the configuration window in which the enabling of the key is highlighted.

Once your user has been entered, the system will enable the access screens or menus, which are located in the upper part of the supervision system, it is available throughout the project. Through these menus we can enter any screen according to the user's requirement. These menus display a collection of screens classified by function; as evidence of the above, Fig. 9 is shown.

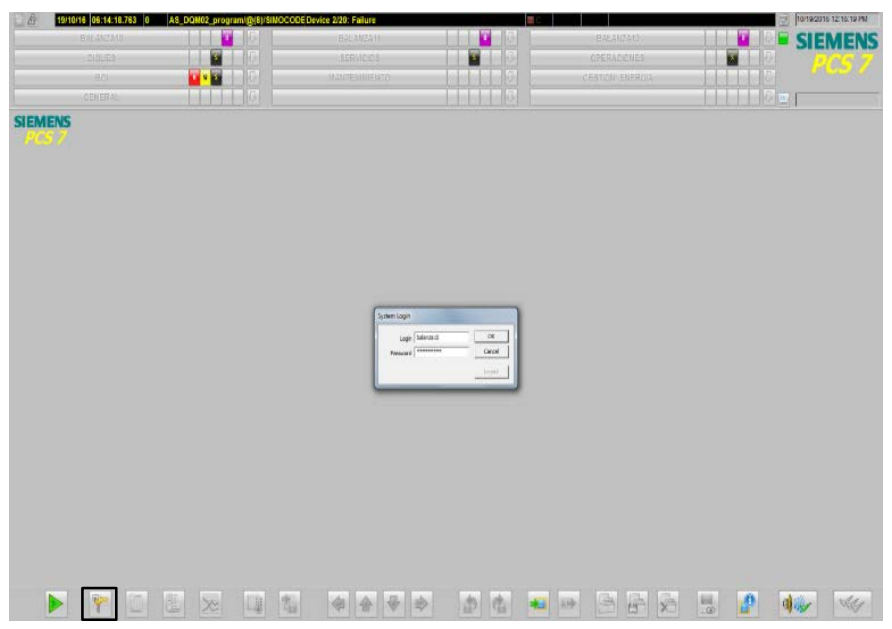

Fig. 8. Configuration of Restricted Access to the SCADA System.

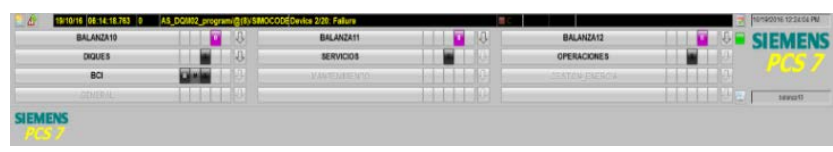

Fig. 9. SCADA System Supervision Menus Configuration.

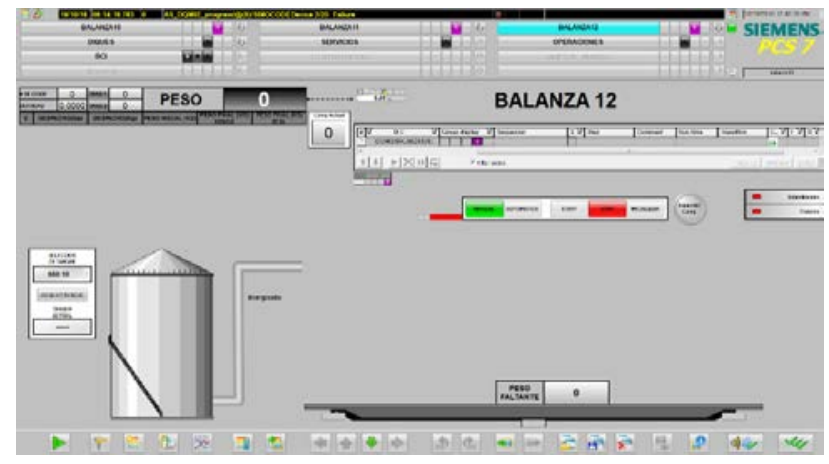

Fig. 10. Setting the Balance Selection in the SCADA System.

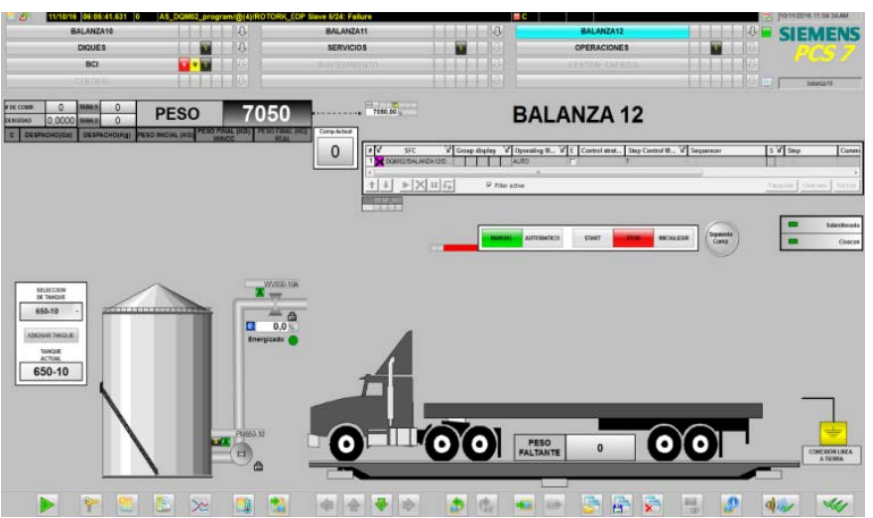

Fig. 11. Configuration of the Tank Selection and Start of the Dispatch Process, in the SCADA System.

Once the scale is entered from where the chemical product will be dispensed, the selected scale will be indicated by the background color of the selected tab. Once located on the balance, the following distribution will be available as shown in Fig. 10.

This is also configured to make the selection of the tank, which must be correctly located to start the dispatch process. Immediately, the actuator and the displacement pump will be enabled in automatic operating mode, with which the tanker truck or also called container truck will enter the scale platform recording the initial weight, so that next the sensor will be connected overfill and sensor ground, as shown in Fig. 11.

\section{RESUlt AND Discussion}

\section{A. Results}

As a result of the integration of the distributed control system and the SCADA system of the chemical product filling process in Fig. 12, the monitoring and supervision obtained in real time from the SCADA system is already shown, in which the valve is located at a $50 \%$ opening restricting the access of the chemical product, for when the missing weight is less than $300 \mathrm{~kg}$. The displacement pump motor will keep its nominal speed, while in the field the beacon and siren will be active for 3 seconds, with the objective to notify the scale operator of the completion of the chemical product dispatch.

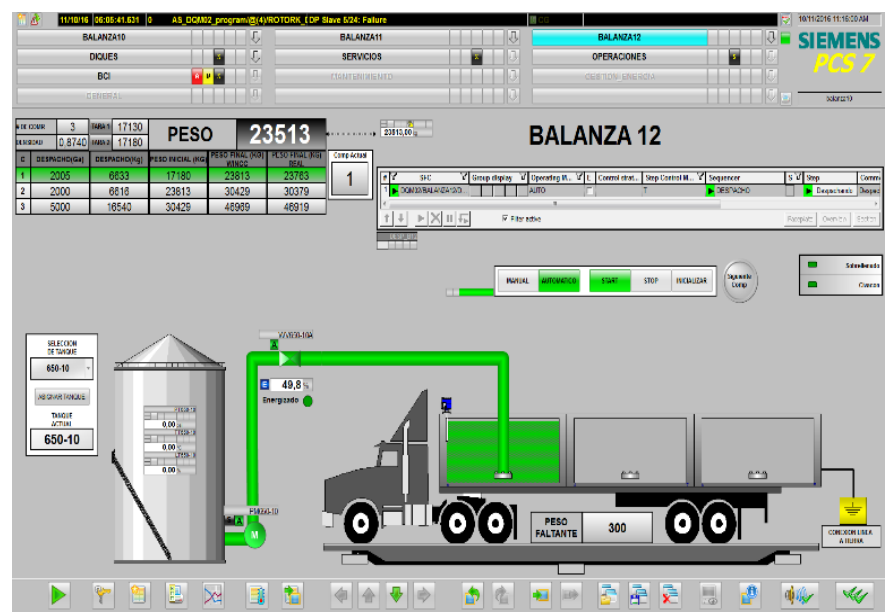

Fig. 12. SCADA System Commissioning: Filling System Control, Valve Restriction to $50 \%$. 


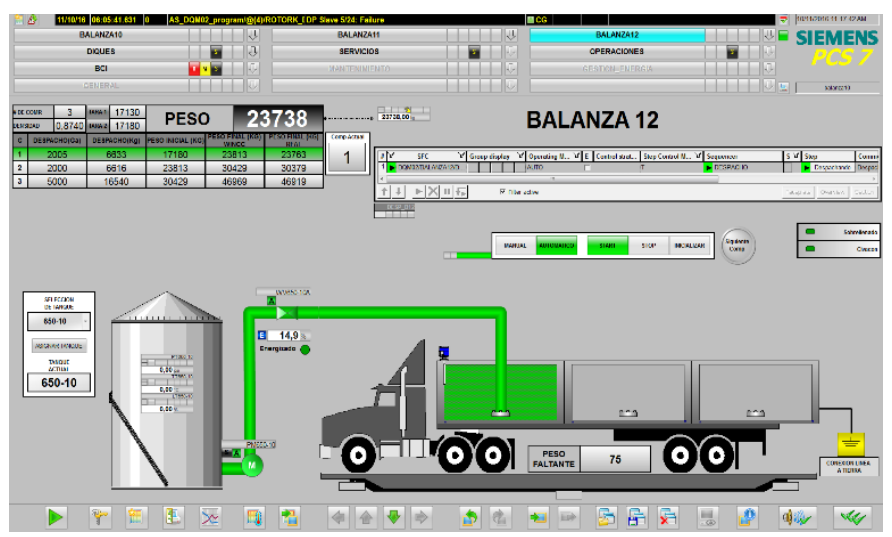

Fig. 13. SCADA System Commissioning: Filling System Control, Valve Restriction to $75 \%$.

In Fig. 13, it is shown that when the missing weight is less than $150 \mathrm{~kg}$, the electric actuator will proceed to close to $75 \%$.

In Fig. 14, it is shown that when the missing weight is less than $75 \mathrm{~kg}$, the electric actuator will proceed to close to $85 \%$.

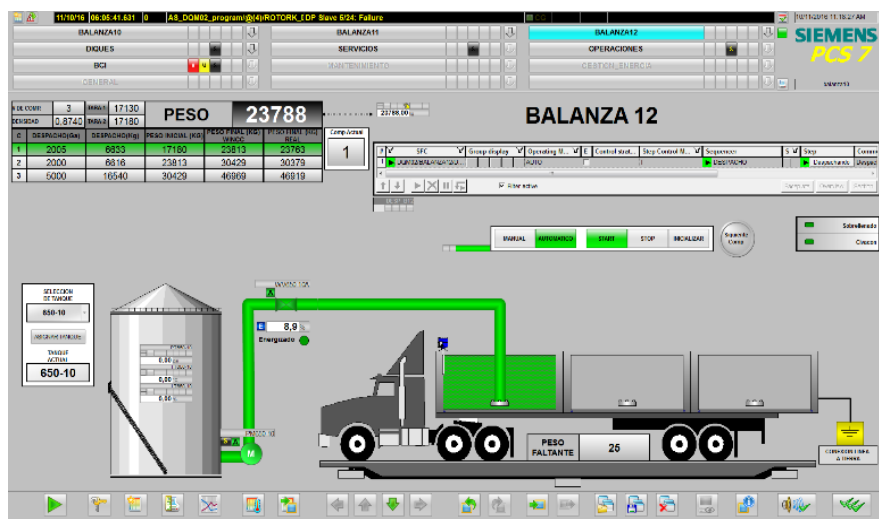

Fig. 14. SCADA System Start-Up: Filling System Control, Valve Restriction to $85 \%$.

Upon reaching the missing weight, the electric actuator will fully close and the displacement pump will stop. The "SenCont_full” button will flash, showing that the dispatch in container 1 has ended, moving on to the next container. As evidence of the above, it is evidenced in Fig. 15.

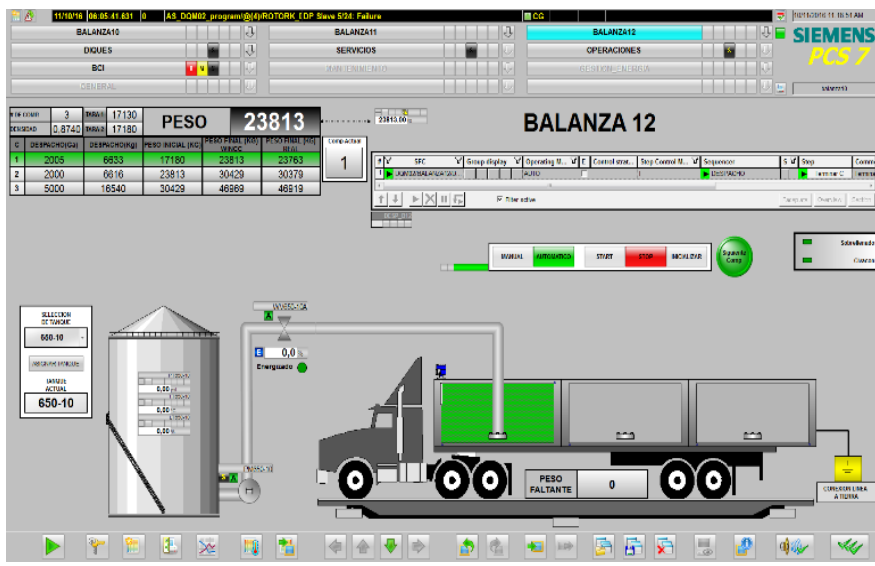

Fig. 15. Commissioning of the SCADA System: Complete Filling of Container 1.

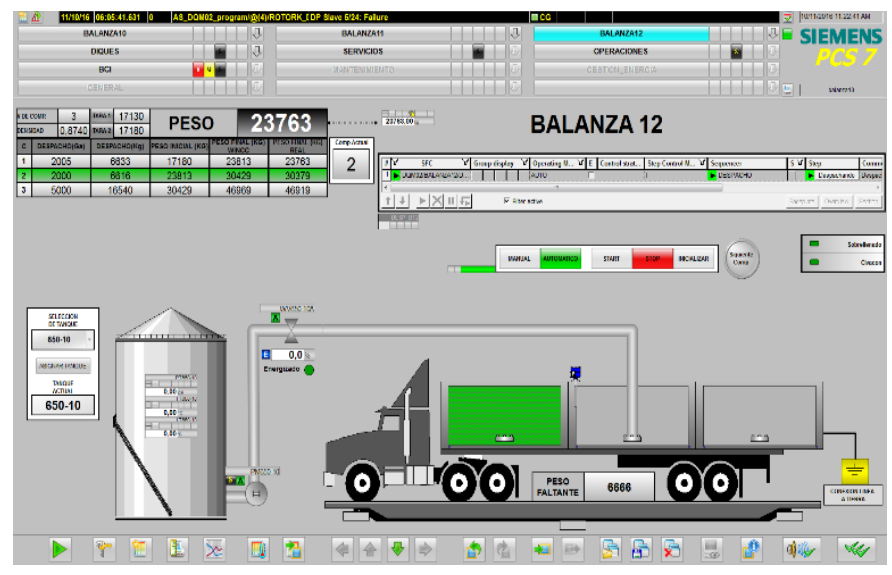

Fig. 16. Commissioning of the SCADA System: Filling Process of Container 2 of the Tank Truck.

In Fig. 16, it is shown that the tank truck tank 2 is automatically filled; for which precision and total elimination of spillage of the chemical product is guaranteed.

\section{B. Discussion}

According to the results evidenced in the screenshots of the SCADA system, it shows correct operability and optimal performance in the chemical product dispatch process, from the integration with the distributed control system developed under the Siemens CP443 controller and structured under an industrial network with Profibus DP protocol and remote station simenes ET 200, in this regard in [8] the author also obtains as a finding an optimal functioning in the integration of the distributed control system of a plant in which the flow of energy is monitored and regulated. raw material; highlighting that his proposed solution is developed using the Profibus DP and Ethernet protocol; however, he used as part of his solution a CP-343 controller also from Siemens and an ET200 peripheral junction terminal. The difference between the controllers used is due to the fact that in my solution proposal, I control a greater number of actuators, sensors and that I seek that the industrial rd has scaling capacity due to terminals projected to be implemented in the future.

Another aspect to highlight is the improvement in filling precision and eliminated any possibility of loss of the chemical product due to spillage, it has significant relevance at the management level because it generates an impact on productivity. In this regard, in [10] the author applies a SCADA system for dosing the entry of basic reagents to three tanks, for which he used, as in the proposed solution, a Siemens 400 controller, in which he evidenced in his research that the Automated system will contribute to the improvement of productivity in the organization. Also in [23] it is highlighted that from the implementation of a SCADA system to a process linked to the improvement of the dosage of components in the stage of crushing and pulverization of inputs, it contributed to the improvement of results in the productivity of the company.

A third point to highlight as part of the development of this article is the contribution to reducing environmental pollution in the work environment; The fact is that when the process of dispatch of inputs or chemical products is automated, there will 
no longer be any spillage, so its impact is on the generation of polluting particles in the environment; In this regard, in [30] the author points out that in his study the distributed control system and the SCADA system showed an optimal functioning of the supervision and control process in liquid petroleum plants, guaranteeing the safety of the work environment and minimizing the conditions abnormal operation of the process.

\section{CONCLUSION}

It is concluded that the distributed control system (DCS), implemented from a Siemens CP443 unit, the same that was structured under the philosophy of an industrial network with Profibus DP protocol, remote station Siemens ET-200, and integrated into a SCADA (developed through the WinCC Runtime Project system) in a chemical product dispatch plant (acetic acid), showed to work optimally and efficiently, guaranteeing a regulation of the container filling or dispatch system composed of 3 compartments of 300 Kilos, the same that regulates from the gradual opening of valves the filling level of acetic acid. The most significant contributions that are generated as an effect of this control are the elimination of the spillage of chemical product as well as the reduction of polluting particles in the work environment and finally improvement of productivity, a relevant aspect at the level of planning, management and direction of the company.

\section{ACKNOWLEDGMENT}

The recognition to J. Yataco-Yataco for his contribution in the information and contributions from his experience obtained in the company.

\section{REFERENCES}

[1] J. Piñeros, "Chemical risk assessment applying the Colombian technical standard at the colsubsidio norte school facilities," Thesis, Jose Francisco de Caldas District University, Colombia, 2020.

[2] A. Bakri, et al., "Addressing the Issues of Maintenance Management in SMEs: Towards Sustainable and Lean Maintenance Approach," Emerging Science Journal, Vol. 5, pp. 367-379, 2021. DOI: http://dx.doi.org/10.28991/ESJ-2021-01283.

[3] K. Sigueñas and M. Tipto, "Logistic improvement for the optimization of the discharge of hazardous materials toluene and xylene from IPE Tralsa,” Thesis, Maritime University of Peru, Peru, 2020.

[4] Z. Villavicencio, "Quality control applied to cleaning products manufactured by a chemical supply warehouse and recording the results in SAP-HANA," Thesis, National University of San Agustín de Arequipa, Perú, 2018.

[5] R. Martinez, "Evaluation of the prevention of attention to spills in linear projects in the hydrocarbon sector: case of oil pipelines," Thesis, University of America, Colombia, 2020.

[6] D. Gutiérrez, "Proposal for the improvement and update of safety and health in chemical inputs for A.G.P de Colombia S.A," Thesis, University Francisco Jose de Calda, Colombia, 2016.

[7] C. Molina, W. Gonzáles and G. Cruz, "An approach to teaching from the CTS approach,” University and Society Jurnal, vol. 10, pp. 221-226, 2018.

[8] O. Chamorro-Atalaya, D. Arce-Santillan, T. Diaz-Leyva and M. DíazChoque, "Supervision and cotrol by SCADA of an automated fire system," Indonesian Journal of Electrical Engineering and Computer Science (IJEECS), Vol. 21, pp. 92-100, 2021. DOI: http://dx.doi.org/10.11.591/ijeecs.v21.i1.pp92-100.

[9] L. Silva-Diaz, Y. Hernández-López and A. Vázquez-Peña, “Design of an automation system for the silage plant Hector Molina," Journal of Agricultural Technical Sciences, Vol. 26, pp. 109-120, 2017.
[10] O. Chamorro-Atalaya, D. Goicochea-Vilela, D. Arce-Santillan, M. DíazChoque and T. Diaz-Leyva, "Automation of the burner of a pirotubular boiler to improve the efficiency in the generation of steam," Indonesian Journal of Electrical Engineering and Computer Science (IJEECS), Vol. 21, pp. 101-109, 2021. DOI: http://dx.doi.org/10.11.591/ijeecs. v21.i1.pp101-109.

[11] J. Moscoso, "Integration of different distributed control systems (DCS) using standard software and OPC technology," Thesis, National University of San Agustín de Arequipa, Perú, 2014.

[12] S. Marzal, "Conception and Integration of Architectures and communication protocols within Intelligent Microgrids supervision and Control systems,” Thesis, Polytechnic university of Valencia, España, 2019.

[13] J. Simó-Ten, J. Poza-Lujan, J. Posadas-Yague and F.Blanes, "Study and implementation of Middleware for distributed control applications," XXXVIII Automatic Conference, Vol. 1, pp. 942-951, 2020. DOI: http://dx.doi.org/10.17979/spudc.9788497749.0942.

[14] D. Aguirre, "Development of a SCADA system for use in small and medium-sized companies,” Thesis, University of Piura, Perú, 2013.

[15] U. Sohail, M. Muneer and F. Khan, "An efficient aproach of load shifting by using SCADA", Advances in Science, Technology and Engineering Systems Journal (ASTES), Vol. 1, pp. 1-6, 2016. DOI: http://dx.doi.org/10.25046/aj010301.

[16] M. Syamsul, Susanto, D. Stiawan, M. Yazid and R. Budiarto, "The trends of supervisory control and data acquisition security challenges in heterogeneous networks," Indonesian Journal of Electrical Engineering and Computer Science (IJEECS), Vol. 22, pp. 874-883, 2021. DOI: http://dx.doi.org/10.11591/ijeecs.v22.i2.pp874-883.

[17] M. Varghese, A. Manjunatha and T. Snehaprabha, “ method for improving ripple reduction during phase shedding in multiphase buck converters for SCADA systems," Indonesian Journal of Electrical Engineering and Computer Science (IJEECS), Vol. 24, pp. 29-36, 2021. DOI: http://dx.doi.org/10.11591/ijeecs.v24.i1.pp29-36.

[18] E. Pérez-López, “SCADA Systems in the Industrial Automation," Technology in March Journal, Vol. 28, pp. 3-14, 2015.

[19] A. Soetedjo, A. Lomi and Y. Nakhoda, "Smart grid Testbed using SCADA software and Xbee Wireless Communication,” International Journal of Advanced Computer Science and Applications (IJACSA), Vol. 6, pp. 86-92, 2015. DOI: http://dx.doi.org/10.14569/IJACSA. 2015.060811.

[20] M. Lakhoua, B. Hamounda, R. Glaa and E. Amraoui, "Contributions to the Analysis and the Supervision of a Thermal Power Plant," International Journal of Advanced Computer Science and Applications (IJACSA), Vol. 7, pp. 93-101, 2016. DOI: http://dx.doi.org/10.14569/ IJACSA.2016.07 0213.

[21] N. Gaitan, "MCIP Client Application for SCADA in Liot Environment," International Journal of Advanced Computer Science and Applications (IJACSA),Vol. $\quad 6, \quad$ pp. 2015. DOI: http://dx.doi.org/10.14569/ IJACSA.2015.06 0921.

[22] T. Simona-Anda, “A solution for the Uniform Integration of field devices in an industrial Supervisory Control and Data Acquisition System," International Journal of Advanced Computer Science and Applications (IJACSA), Vol. 9, pp. 319-323, 2018. DOI: http://dx.doi.org/10.14569/IJACSA.2018.090344.

[23] M. Bernal and D. Jimenez, "Risk management proposal for SCADA in electrical systems,” USBMed Journal, Vol. 3, pp. 12-21, 2012.

[24] J. Ochoa-Hernandez, M. Barcelo-Valenzuela, F. Cirett-Galán and R. Luque-Morales, "A model to develop SCADA-type systems in productive environments," Computing and Systems Journal, Vol. 22, pp. 1543-1558, 2018. DOI: http://dx.doi.org/10.13053/CyS-22-4-2823.

[25] I. Tawiah, U. Ashraf, Y. Song and A. Akhtar, "Marine Engine room alarm Monitoring System," International Journal of Advanced Computer Science and Applications (IJACSA), Vol. 9, pp. 319-323, 2018. DOI: http://dx.doi.org/10.14569/IJACSA.2018.090659.

[26] L. Rajesh and P. Satyanarayana, "Detecting Flooding attacks in communicacition protocol of Industrial Control Systems,” International Journal of Advanced Computer Science and Applications (IJACSA), Vol. 11, pp. 396-401, 2020. DOI: http://dx.doi.org/10.14569/IJACSA. 2020.0110149 . 
[27] L. Barzaga, R. Mompie and B. Valdés, "SCADA systems for the automation of the CIGB production processes," RIELAC Journal, Vol. 37, pp. 20-37, 2016. http://scielo.sld.cu/scielo.php?script =sci_abstract\& pid=S1815-59282016000100003.

[28] G. Tzokatziou, L. Maglaras, H. Janicke and Y. He, "Exploiting SCADA vulnerabilities usig a Human Interface Device,” International Journal of Advanced Computer Science and Applications (IJACSA), Vol. 6, pp. 234-241, 2015. DOI: http://dx.doi.org/10.14569/IJACSA.2015.060731.

[29] Y. Chatei, E. Ar-Reyouchi, M. Hammouti and K. Ghoumid, "Dowlink and Uplink mesaage siza impact on round trip time metric in Multi-Hop Wireless mesh Networks," International Journal of Advanced Computer Science and Applications (IJACSA), Vol. 8, pp.223-229, 2017. DOI: http://dx.doi.org/10.14569/IJACSA.2017.080332.

[30] T. Simona-Anda, "Performances Analysis of a SCADA Architecture for Industrial Processes,” International Journal of Advanced Computer Science and Applications (IJACSA), Vol. 8, pp. 456-460, 2017. DOI: http://dx.doi.org/10.14569/IJACSA.2017.081155.

[31] K. Chkara and H. Seghiouer, "Criteria to Implement a Supervision System in the Pretroleum Industry: A Case in a Terminal Storage Facility," Advances in Science, Technology and Engineering Sytems Journal (ASTES), Vol. 5, pp. 29-38, 2020. DOI: http://dx.doi.org/ 10.25.046/aj050505.

[32] O. Chamorro-Atalaya, J. Yataco-Yataco and D. Arce-Santillan, "Industrial network for the control and supervision of the acetic acid dispatch process, and its influence on the reduction of chemical contaminants for operators," Advances in Science, Technology and Engineering Systems (ASTES), vol. 5, pp. 13-20, 2020. DOI: http://dx.doi.org/10.25046/aj050103.

[33] O. Chamorro-Atalaya, A. Sanchez-Ayte, C. Dávila-Ignacio, O. OrtegaGalicio, N. Alvarado-Bravo and A. Torres-Quiroz, “Automatic control of motors through Simocode pro, and its effect on the performance of the process of filling and dispensing of chemical inputs," Indonesian Journal of Electrical Engineering and Computer Science (IJEECS), Vol. 23, pp. 179-187, 2021. DOI: http://dx.doi.org/10.11591/ijeecs.v23.i1. pp179-187.

[34] J. Yataco-Yataco, "Design of an industrial network for the control and supervision of the product dispatch process chemicals, to reduce the operator's exposure to harmful vapors in the company Chemical Deposits Mineros S.A.,” Thesis, Alas Peruanas University, Perú, 2018.

[35] X. Qin and Y. Tang, “Design of Intelligent Drop Fuse,” Journal of Human, Earth, and Future, Vol. 1, pp. 146-152, 2020. DOI: http://dx.doi.org/10. 28991/HEF-2020-01-03-04.

[36] I. H. Wayangkau, et al. "Utilization of IoT for Soil Moisture and Temperature Monitoring System for Onion Growth,” EmergingScience Journal, Vol. 4, pp. 102-115, 2021. DOI: http://dx.doi.org/10.28991/esj2021-SP1-07. 